\title{
Design of an Ultrawideband Circularly Polarized Printed Crossed-Dipole Antenna Based on Genetic Algorithms for S-Band CubeSat Applications
}

\author{
Jorge Simon $\left(\mathbb{D},{ }^{1}\right.$ Hugo Perez-Guerrero, ${ }^{2}$ Jorge Sosa-Pedroza ${ }^{(\mathbb{D},},{ }^{3}$ Fabiola Martínez-Zúñiga, ${ }^{3}$ \\ Juvenal Villanueva-Maldonado, ${ }^{1}$ Jorge Flores-Troncoso $\left(i D,{ }^{4}\right.$ \\ and Marco Cardenas-Juarez (i) $^{2}$ \\ ${ }^{1}$ Cátedras CONACYT, Unidad Académica de Ingeniería Eléctrica, Universidad Autónoma de Zacatecas, Zacatecas, Mexico \\ ${ }^{2}$ Facultad de Ciencias, Universidad Autónoma de San Luis Potosí, San Luis Potosí, Mexico \\ ${ }^{3}$ Escuela Superior de Ingeniería Mecánica y Eléctrica, Unidad Adolfo López Mateos, Instituto Politécnico Nacional, \\ Ciudad de México, Mexico \\ ${ }^{4}$ Unidad Académica de Ingeniería Eléctrica, Universidad Autónoma de Zacatecas, Zacatecas, Mexico
}

Correspondence should be addressed to Marco Cardenas-Juarez; marco.cardenas@uaslp.mx

Received 16 June 2021; Revised 5 August 2021; Accepted 18 August 2021; Published 10 September 2021

Academic Editor: Claudio Gennarelli

Copyright (C) 2021 Jorge Simon et al. This is an open access article distributed under the Creative Commons Attribution License, which permits unrestricted use, distribution, and reproduction in any medium, provided the original work is properly cited.

As in any satellite, onboard antennas for CubeSats are crucial to establish communication with ground stations or other satellites. According to its application, antennas must comply with standardized requirements related to size, bandwidth, operating frequency, polarization, and gain. This paper presents an ultrawideband circularly polarized two-layer crossed-dipole microstrip antenna for S-band CubeSat applications using genetic algorithms optimization tools included in the 3D electromagnetic simulation software Ansys HFSS. The antenna is constructed on a $10 \times 10 \mathrm{~cm}$ Cuclad-250 substrate with a back copper flat plane, located at $\lambda / 4$ at $2.25 \mathrm{GHz}$ operating frequency. The backplane with the exact substrate dimensions improves gain and reduces inside satellite radiation. Measured bandwidth defined by $\mathrm{S}_{11}$ at a $-10 \mathrm{~dB}$ was higher than $1835 \mathrm{MHz}$ with $\mathrm{S}_{11}=-24.68 \mathrm{~dB}$ at the central frequency of $2.25 \mathrm{GHz}$, while measured VSWR at the same frequency was 1.124 . At $2.25 \mathrm{GHz}$, the maximum measured gain and the minimum measured axial ratio in the broadside direction were found to be $6 \mathrm{dBi}$ and $0.22 \mathrm{~dB}$, respectively. There are antenna simulations and measurements, as long as its fabrication guarantees application requirements that make it ready for prespace testing.

\section{Introduction}

According to mass and size, CubeSat belongs to a satellite classification called nanosatellites, which follow the standard proposed in 1999 by Jordi Puig-Sauri from CalPoly San Luis Obispo and Bob Twiggs from Stanford University to enable access to space for university students. However, since then, the standard has been adopted by hundreds of organizations worldwide, not only for educational purposes. The CubeSat standard simplifies frequent and affordable access to space for many applications. CubeSat design protocol specifies a maximum mass of $1.3 \mathrm{~kg}$ and maximum outer dimensions of $10 \mathrm{~cm}$ per side for a one-unit ( $1 \mathrm{U}$ ) version, although $2 \mathrm{U}$ or $3 \mathrm{U}$ or bigger versions are acceptable. Like any other wireless telecommunication system, CubeSat includes an antenna that must comply with standard requirements as weight, size, compactness, operating frequency, linear or circular polarization, impedance matching, bandwidth, and gain. Depending on its application, most CubeSats antennas work in $\mathrm{S}, \mathrm{C}$, and $\mathrm{X}$ bands $[1,2]$.

The $\mathrm{S}, \mathrm{C}$, and $\mathrm{X}$ band antennas must be designed to comply with the dimensions to fit on the $10 \times 10 \mathrm{~cm}$ area of a CubeSat side face and with a gain of around $10 \mathrm{dBi}$. Thus, planar structures are well-suited for CubeSats antennas, as those presented in Table 1 for S-band frequencies. 
TABle 1: Some S-band planar antennas for CubeSats.

\begin{tabular}{|c|c|c|c|c|c|c|}
\hline Type of antenna & $\begin{array}{c}\text { Antenna } \\
\text { height }(\mathrm{mm})\end{array}$ & $\begin{array}{c}\text { Type of } \\
\text { polarization }\end{array}$ & $\begin{array}{c}3 \mathrm{~dB} \text { axial } \\
\text { bandwidth }(\mathrm{GHz})\end{array}$ & $\begin{array}{c}\text { Operating } \\
\text { frequency }(\mathrm{GHz})\end{array}$ & $\begin{array}{c}-10 \mathrm{~dB} \\
\text { bandwidth } \\
(\mathrm{GHz})\end{array}$ & $\begin{array}{l}\text { Maximum } \\
\text { gain }(\mathrm{dB})\end{array}$ \\
\hline Rectangular patch array [3] & 1.59 & Not reported & Not reported & 2.468 & Not reported & 9.6 \\
\hline F-shaped patch $[4]$ & 20.8 & Not reported & Not reported & 2.45 & 1.121 & 8.51 \\
\hline $\begin{array}{l}\text { Planar open-loop standing- } \\
\text { wave radiator [5] }\end{array}$ & 3.16 & Circular & 0.31 & 2.45 & 0.25 & 5.7 \\
\hline Koch snowflake fractal [6] & 1.54 & Not reported & Not reported & 2.3 & 0.2 & 4.39 \\
\hline Cross rhombic [7] & 5.6 & Circular & Not reported & 2.4 & 0.1 & 7.9 \\
\hline $\begin{array}{l}\text { Closed-loop traveling } \\
\text { wave [8] }\end{array}$ & 3.175 & Circular & 0.2 & 2.45 & 0.285 & 5.4 \\
\hline $\begin{array}{l}\text { Metamaterial antenna } \\
\text { integrated with solar cells [9] }\end{array}$ & 1.6 & Circular & 0.05 & 2.25 & 0.25 & 4.87 \\
\hline
\end{tabular}

In this article, the design of an S-band antenna to be used in CubeSats is presented. The antenna complies with onboard antenna physical dimensions required by the CubeSat standard $[1,2]$. It is an ultrawideband circularly polarized printed crossed-dipole antenna (UCPCA), made of a two-layer Cuclad-250 printed circuit board (PCB), working at $2.25 \mathrm{GHz}$.

\section{Antenna Design Using Genetic Algorithms}

For the UCPCA design, the optimization tools based on genetic algorithms (random search) included in the $3 \mathrm{D}$ electromagnetic simulation software Ansys HFSS were applied. The optimization process tunes a set of input parameters to characterize a device, a mathematical process, or an experiment to find the desired minimum or maximum output quantities. The input generally consists of parameters, and they self-define the system to optimize. The cost function or fitness function is used to look for the lower parameter error during the process. The process ends when the parameters found an acceptable fitness. The method uses a stochastic process to optimize solutions to most problems related to electromagnetic theory. A genetic algorithm is modeled on the principles and concepts of natural selection and evolution, hence their name; it has excellent heuristic power, making it more effective when solving complex and combinatorial problems, as is the design of new antenna geometries. The genetic algorithm technique defines cost function as composed of multiple objectives, each with an assigned weight and giving each one a unique number as a solution. It is particularly effective when the objective is to find a global optimization of a high number of parameters ranging a vast solution magnitude, such as the optimization of antenna parameters, for example, reflection coefficient $\left(\mathrm{S}_{11}\right)$, Voltage Standing Wave Ratio (VSWR), and axial ratio (AR) $[10,11]$. Figure 1 shows the flowchart of a simple genetic algorithm.

2.1. Optimization. When using the genetic algorithm optimization technique to find geometry dimensions of the UCPCA that make the model meet the proposed design objectives, $\mathrm{VSWR}<1.7$ and $\mathrm{AR}<1 \mathrm{~dB}$ were defined as objective parameters. The cost function is composed of multiple objectives, with weights and distinctive values; then, optimization process uses the error function given by

$$
\operatorname{err}= \begin{cases}0, & \text { for }\left\{S_{\mathrm{VSWR}} \leq G_{\mathrm{VSWR}}\right\} \cap\left\{S_{\mathrm{AR}} \leq G_{\mathrm{AR}}\right\}, \\ \left(W_{\mathrm{VSWR}}+W_{\mathrm{AR}}\right)\left(S_{\mathrm{AR}}-G_{\mathrm{AR}}\right), & \text { for }\left\{S_{\mathrm{VSWR}} \leq G_{\mathrm{VSWR}}\right\} \cap\left\{S_{\mathrm{AR}}>G_{\mathrm{AR}}\right\}, \\ \left(W_{\mathrm{VSWR}}+W_{\mathrm{AR}}\right)\left(S_{\mathrm{VSWR}}-G_{\mathrm{VSWR}}\right), & \text { for }\left\{S_{\mathrm{VSWR}}>G_{\mathrm{VSWR}}\right\} \cap\left\{S_{\mathrm{AR}} \leq G_{\mathrm{AR}}\right\}, \\ \left(W_{\mathrm{VSWR}}+W_{\mathrm{AR}}\right)\left\{\left(S_{\mathrm{AR}}-G_{\mathrm{AR}}\right)+\left(S_{\mathrm{VSWR}}-G_{\mathrm{VSWR}}\right)\right\}, & \text { for }\left\{S_{\mathrm{VSWR}}>G_{\mathrm{VSWR}}\right\} \cap\left\{S_{\mathrm{AR}}>G_{\mathrm{AR}}\right\},\end{cases}
$$

where $W_{\mathrm{VSWR}}$ and $W_{\mathrm{AR}}$ are the assigned weights, $G_{\mathrm{VSWR}}$ and $G_{\mathrm{AR}}$ are the target values proposed at the beginning of the process, and $S_{\mathrm{VSWR}}$ and $S_{\mathrm{RA}}$ are the values obtained by each iteration. Subindexes VSWR and AR imply the UCPCA parameters considered for optimization.

2.2. The Crossed-Dipole Antenna. The UCPCA is made of two orthogonal circular planar dipoles to produce circular polarization. Both dipoles are fed in quadrature, using a $\lambda_{r} / 4$ curved transmission line for the required 90-degree phase shift $\left(\lambda_{r}\right.$ wavelength for Cuclad-250). For each dipole, one half is printed on the upper side of the substrate, while the other halves are on the lower side. The UCPCA initial desired parameters were $f_{\mathrm{D}}=2.25 \mathrm{GHz}$ (frequency of interest), BW $>1 \mathrm{GHz}, \mathrm{S}_{11}<-10$ $\mathrm{dB}, G>6 \mathrm{dBi}$, VSWR $<1.7$, and $\mathrm{AR}<1 \mathrm{~dB}$. The design was supported by previous experiences in ultrawideband antennas using circular and elliptical structures to enhance bandwidth [12]. In this case, an initial cross-dipole configuration was used.

As it is well-known, $\lambda / 4$ microstrip transmission lines are of common use as phase shifters to produce circular polarization. Therefore, in order to follow the wideband idea, 


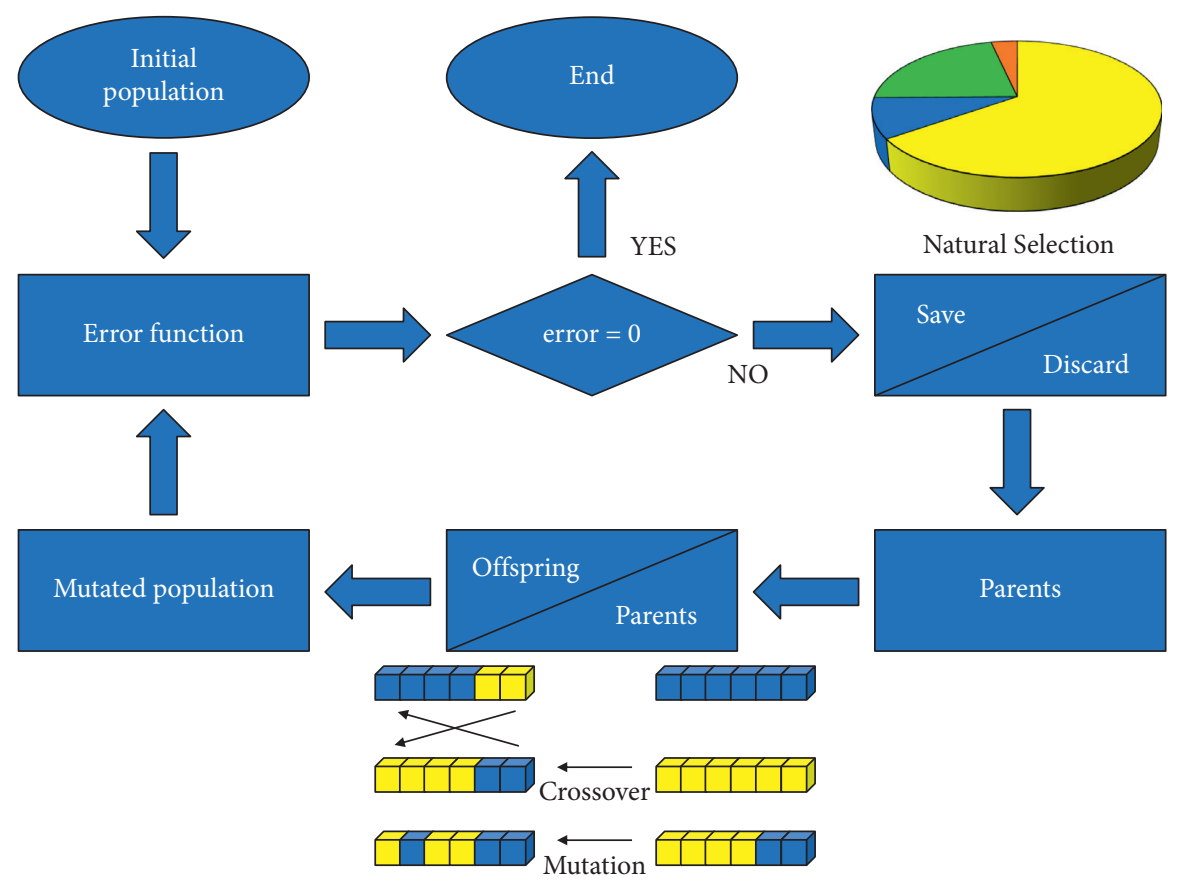

Figure 1: Flowchart of a simple genetic algorithm.

the use of a curved microstrip transmission line was selected [13]. The contribution implies dividing both monopoles, printing each half of them on the upper side and the downside of the substrate, and leaving space for the curved microstrip transmission line. Figure 2 shows the original idea to be optimized by genetic algorithms; it describes one side of the UCPCA and includes the curved transmission line; $L_{1}$ and $W_{1}$ define the connector area, which goes from one monopole to the other to generate circular polarization, which in this work was right hand.

Genetic algorithm configuration is shown in Table 2, being worth mentioning that uniform and Gaussian distributions for crossover and mutation operation were selected, respectively. Table 3 defines ranges for geometry variables (described in Figure 2) considered in the optimization process. All dimensions are defined on a substrate whose relative permittivity is $\varepsilon_{r}=2.5 \pm 0.1$ (Cuclad-250), where $\lambda_{\text {sub }}=8.432 \mathrm{~cm}$ at $f_{D}=2.25 \mathrm{GHz}$, except for the $\lambda_{0} / 4$ (free space) distance $\mathrm{H}$ between antenna and reflector plane, where $\lambda_{0}=13.33 \mathrm{~cm}$ at $f_{D}$. Dimensions for antenna substrate are SubH for thickness and SubX and SubY for both sides.

Table 4 shows a comparison of simulation results before and after genetic algorithm optimization, including gain, $S_{11}$, and axial ratio at $f_{\mathrm{D}}=2.25 \mathrm{GHz}$; likewise, bandwidth at $-10 \mathrm{~dB}$ is shown. As seen, genetic algorithm optimization improves goal parameters: $S_{11}$ and $A R$, without altering gain. Figures 3(a) and 3(b) compare the original design with the final optimization geometry using the same scale of $1 \mathrm{~cm}^{2}$ for each square. Figure 4 shows the side view of the proposed antenna including the coaxial cable for feeding purposes. In this figure, it can be seen that the total antenna height is $3.604 \mathrm{~cm}(H+2 \mathrm{SubH})$ and that although it is large compared to the length of one side of the CubeSat $(10 \mathrm{~cm})$ or with other

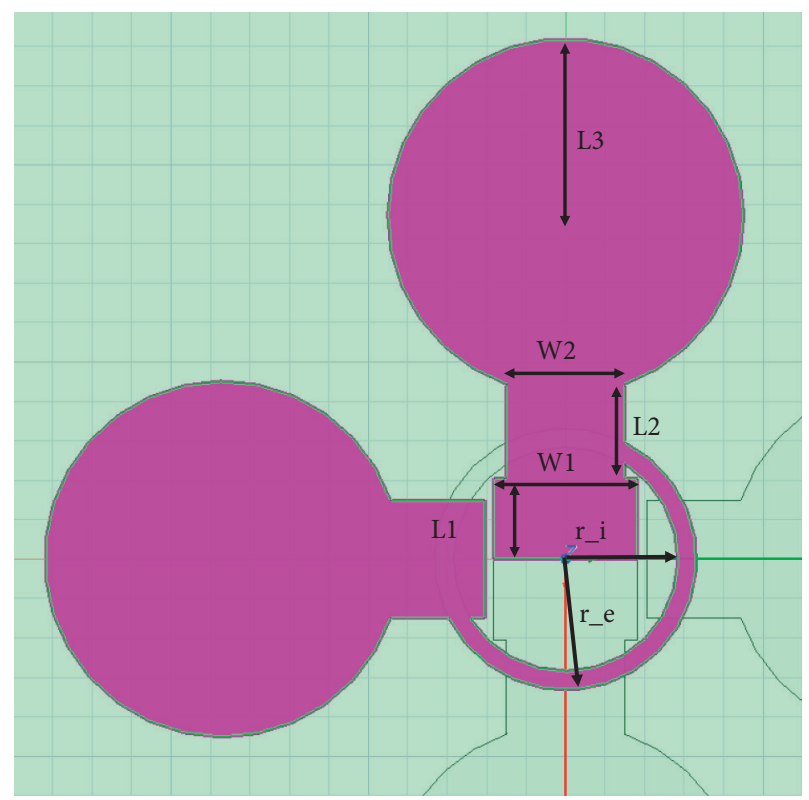

Figure 2: Geometry dimensions considered for UCPCA optimization.

TABLE 2: Configuration of the genetic algorithms.

\begin{tabular}{lc}
\hline Parameter & Value \\
\hline Maximum number of generations & 1,500 \\
Maximum simulation time & $32,400 \mathrm{~s}$ \\
Parents & 35 individuals \\
Mating chromosomes & 35 individuals \\
Offspring & 35 individuals \\
Survivors & 15 individuals \\
New generation & 25 individuals \\
\hline
\end{tabular}


TABLE 3: Ranges of geometry dimensions for UCPCA optimization.

\begin{tabular}{lcccc}
\hline Variable & Final value $\left(\mathrm{cm}\right.$ and $\left.\lambda_{\text {sub }}\right)$ & Initial value $(\mathrm{cm})$ & Minimum value $(\mathrm{cm})$ & Maximum value $(\mathrm{cm})$ \\
\hline$W_{2}$ & $0.6=0.07 \lambda_{\text {sub }}$ & 0.5 & 0.1 & 1 \\
$W_{1}$ & $0.728=0.08 \lambda_{\text {sub }}$ & 0.5 & 0.1 & 1 \\
$L_{3}$ & $0.902=0.1 \lambda_{\text {sub }}$ & 0.5 & 0.5 & 0.2 \\
$L_{2}$ & $0.476=0.05 \lambda_{\text {sub }}$ & 0.4 & 0.2 & 0.8 \\
$L_{1}$ & $0.409=0.04 \lambda_{\text {sub }}$ & 0.4 & 0.3 & 0.8 \\
$r_{\mathrm{i}}$ & $0.568=0.06 \lambda_{\text {sub }}$ & 0.4 & Fixed & 1 \\
$r_{e}$ & $0.664=0.07 \lambda_{\text {sub }}$ & 0.75 & Fixed & Fixed \\
$H$ & $3.3=0.39 \lambda_{\text {sub }}=\lambda_{o} / 4$ & Fixed & Fixed & Fixed \\
SubX & $9.5=1.12 \lambda_{\text {sub }}$ & Fixed & Fixed & Fixed \\
SubY & $9.5=1.12 \lambda_{\text {sub }}$ & Fixed & Fixed & Fixed \\
SubH & $0.152=0.01 \lambda_{\text {sub }}$ & & &
\end{tabular}

TABle 4: Simulation results at $2.25 \mathrm{GHz}$ before and after optimization.

\begin{tabular}{lccccc}
\hline Type of study & $\begin{array}{c}\text { Maximum gain }(\mathrm{dBi}) \\
\text { at } 2.25 \mathrm{GHz}\end{array}$ & $\begin{array}{c}\text { Reflection coefficient } \mathrm{S}_{11} \\
(\mathrm{~dB}) \text { at } 2.25 \mathrm{GHz}\end{array}$ & $\begin{array}{c}-10 \mathrm{~dB} \text { bandwidth } \\
(\mathrm{GHz})\end{array}$ & $\begin{array}{c}\text { Axial ratio }(\mathrm{dB}) \text { at } \\
2.25 \mathrm{GHz}\end{array}$ & $\begin{array}{c}3 \mathrm{~dB} \text { axial ratio } \\
\text { bandwidth }(\mathrm{GHz})\end{array}$ \\
\hline $\begin{array}{l}\text { Before genetic } \\
\text { algorithms }\end{array}$ & 7.37 & -1.75 & Not defined & 20.58 & Not defined \\
$\begin{array}{l}\text { After genetic } \\
\text { algorithms }\end{array}$ & 7.6 & -15.96 & 1.36 & 2.37 & 0.36 \\
\hline
\end{tabular}

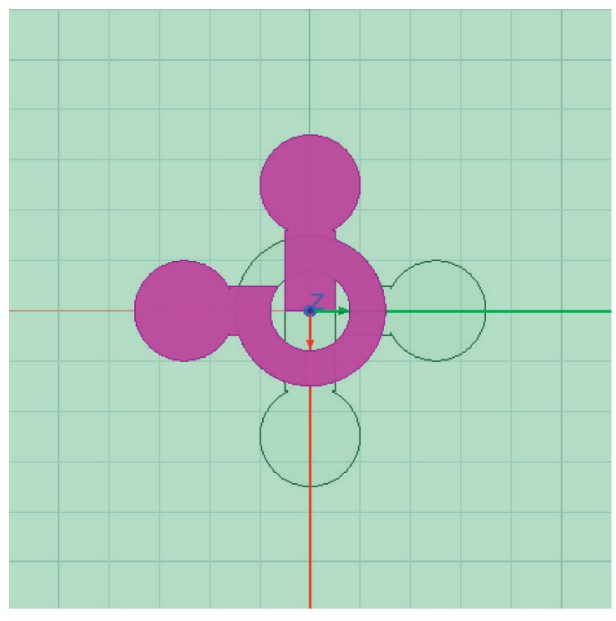

(a)

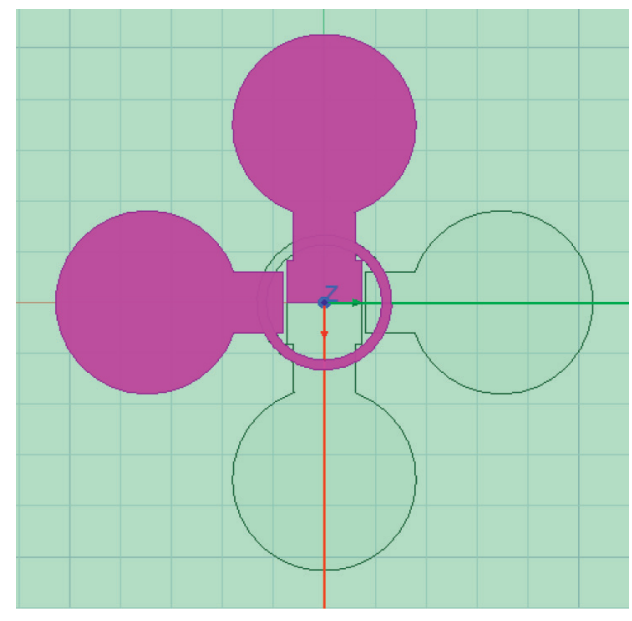

(b)

FIgUre 3: Antenna geometries: (a) before and (b) after optimization.

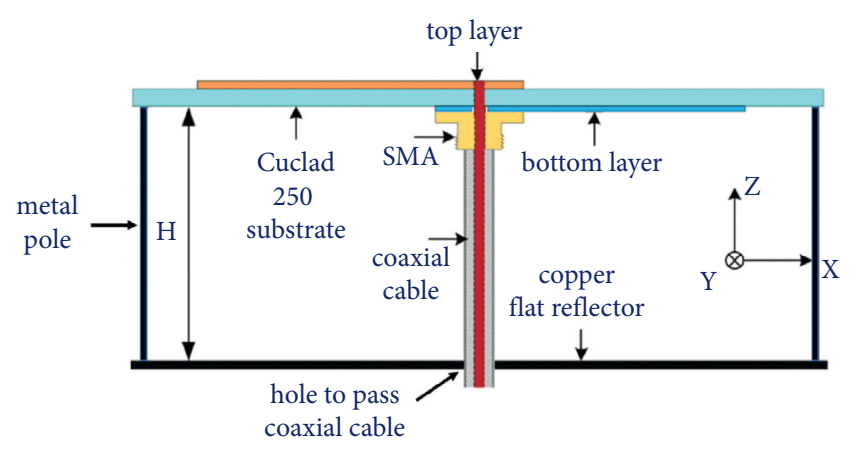

Figure 4: UCPCA side view. antenna designs such as those reported in [3-9] in Table 1, the proposed antenna can be part of a Cubesat of more than $1 \mathrm{U}$, for example, $2 \mathrm{U}, 3 \mathrm{U}$, and so on.

In order to highlight the results obtained through the optimization method based on genetic algorithms, Figure 5 shows a comparison of the antenna parameters between the initial idea and the optimized antenna for $S_{11}, A R$, and gain between 1.5 to $3.5 \mathrm{GHz}$. AR and gain were considered in the broadside direction. Likewise, Figure 6 shows a comparison of $3 \mathrm{D}$ simulated total gain radiation patterns in $\mathrm{dB}$ at $2.25 \mathrm{GHz}$ before and after optimization where there can be seen the maximum gains at $2.25 \mathrm{GHz}$ showed in column 2 of 


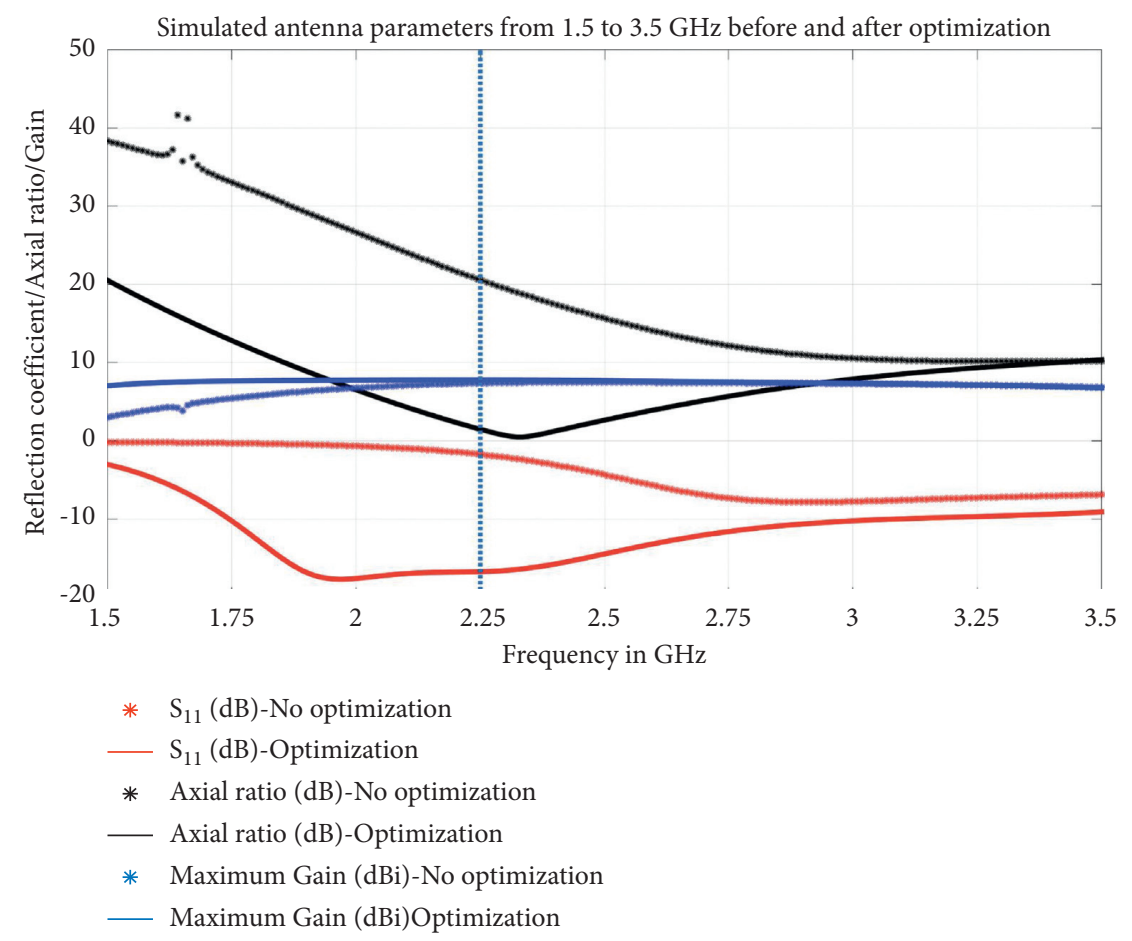

Figure 5: Comparison of simulation antenna parameters before and after optimization.

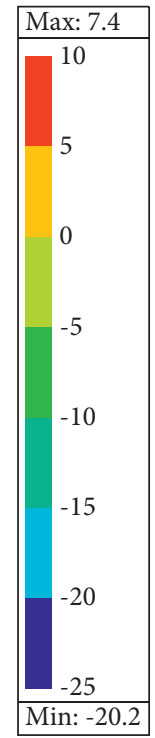

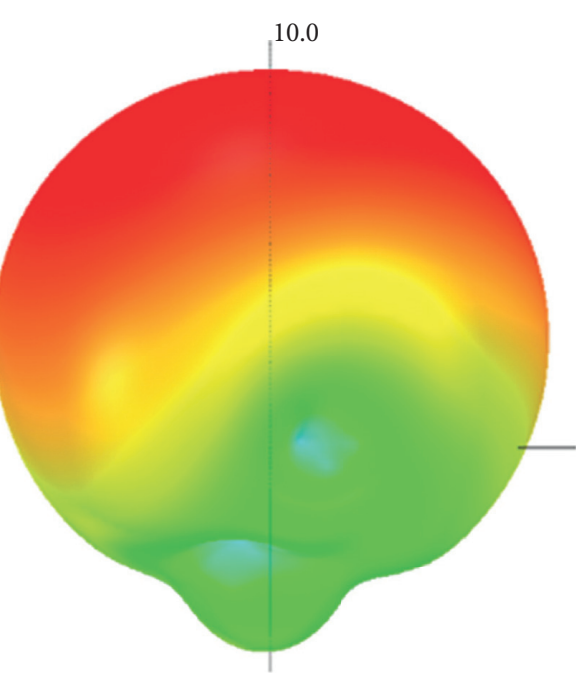

(a)
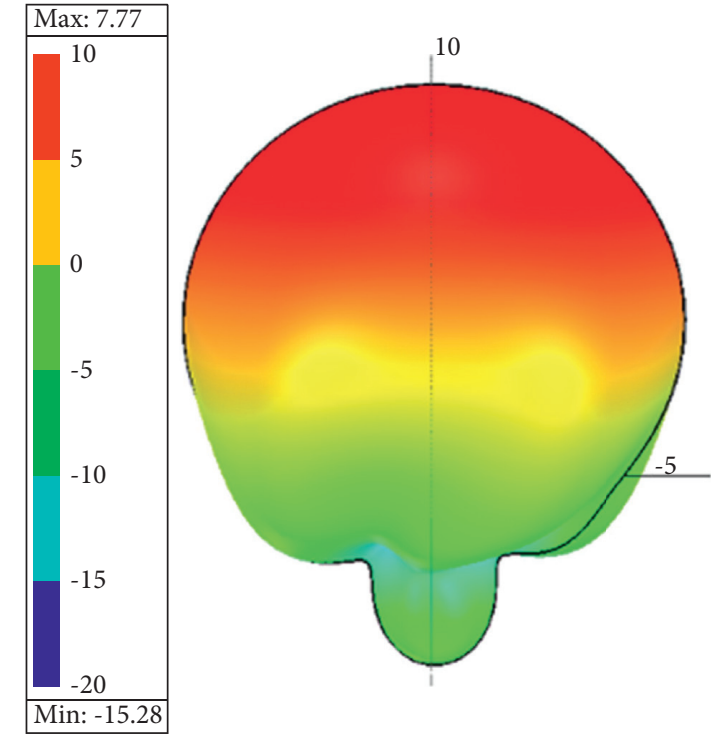

(b)

Figure 6: Comparison of simulated total gain radiation patterns in $\mathrm{dB}$ at $2.25 \mathrm{GHz}$ : (a) before and (b) after optimization.

Table 4. In addition, Figure 7 shows (a) left-hand circular polarization (LHCP) and (b) right-hand (RHCP) simulated gain patterns for the optimized antenna, showing it is RHCP because the maximum for RHCP is $7.5 \mathrm{~dB}$ and for LHCP is $-5.8 \mathrm{~dB}$, with a difference of $13.3 \mathrm{~dB}$ between maximums.

Regarding simulated efficiency for the optimized antenna, it is worth mentioning that incident power to the antenna was $P_{\text {inc }}=10 \mathrm{MW}$, so the radiation efficiency can be seen in Figure 8 , finding a radiation efficiency $e_{r}=97 \%$ at the frequency of interest $f_{D}=2.25 \mathrm{GHz}$. The radiated power at that frequency was $P_{r}=9.7 \mathrm{MW}$, while the losses power was $P_{L}=0.3 \mathrm{MW}$, where radiation resistance $R_{r}=57.6762 \Omega$ and losses resistance $R_{L}=1.7838 \Omega$. The antenna reactance was $X_{A}=14.57 \Omega$, which at $2.25 \mathrm{GHz}$ implies an inductance of $1.03 \mathrm{nH}$. The source $(2.25 \mathrm{GHz})$ has a purely real internal impedance of $Z_{S}=50$ ohms, a voltage magnitude of $\left|V_{g}\right|=2.02 \mathrm{~V}$, and the magnitude of the electric current through the Thevenin's equivalent was $\left|I_{S}\right|=18.3 \mathrm{~mA}$. Figure 9 shows the antenna circuit analysis. 

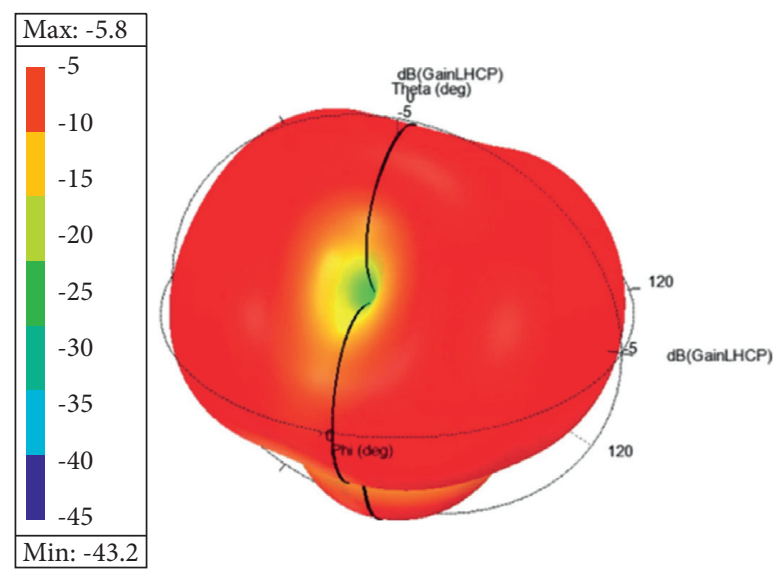

(a)
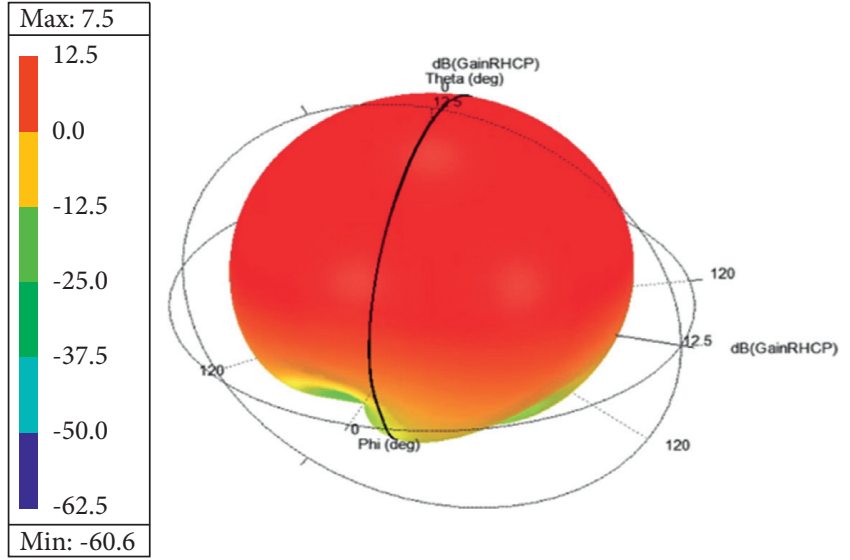

(b)

Figure 7: Simulated LHCP and RHCP gain patterns for the optimized antenna.

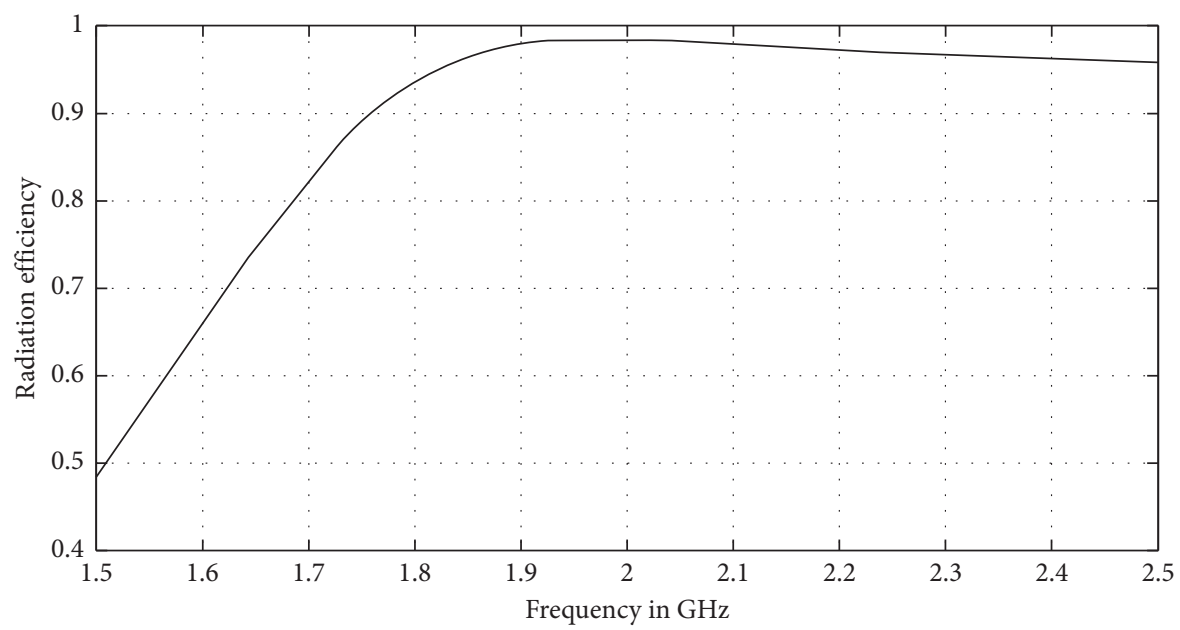

FIGURE 8: Antenna radiation efficiency.

By simulating the optimized antenna through a wider frequency sweep from 0.5 to $13.5 \mathrm{GHz}$ and to study resonances, it can be observed that there are 6 resonance frequencies (null antenna reactance): $f_{r 1}, f_{r 2}, f_{r 3}, f_{r 4}, f_{r 5}$, and $f_{r 6}$, where frequencies $f_{r 3}$ and $f_{r 5}$ are the ones at which antenna resistance is close to the lumped port impedance $(50 \Omega)$. Table 5 shows impedances and $\mathrm{S}_{11}(\mathrm{~dB})$ at resonance frequencies. In addition, in the last line of Table 5, impedance and $\mathrm{S}_{11}(\mathrm{~dB})$ at $f_{D}=2.25 \mathrm{GHz}$, which is the frequency of interest in this work, are included in order to show the acceptable antenna behavior.

Finally, in order to verify that circular polarization is generated, at resonance frequencies $f_{r 3}=1.91 \mathrm{GHz}$ and $f_{r 5}=6.53 \mathrm{GHz}$, as well as at the frequency of interest $f_{D}=2.25 \mathrm{GHz}$, surface electric current distributions are plotted at different instants of time for the proposed antenna in Table 6, where the change of the direction of the arrows with respect to time can be observed.

2.3. UCPCA Construction. UCPCA construction was made by a ProtoMat S104 machine from LPKF with a resolution of $0.2 \mathrm{~mm}$, required to manufacture microwave and radiofrequency devices [14]. Optimized values in column 2 of Table 3 were used in Altium Designer Software to create drawing files [15] required by ProtoMat S104. Drawing files included cuts for antenna shape and holes for the SMA connector. To reduce excessive roughed down work for the ProtoMat S104 machine, only areas near dipoles were cut in this way, so the remaining copper was removed using a traditional abrasion process based on ferric chloride solution. Once the abrasion process was finished, the central conductor of the SMA connector was soldered into the upper side of the antenna and the connector body to the bottom of the structure. Figure 10 depicts (a) top and (b) bottom antenna faces, where the main dipole is vertically located. The total length for each dipole is $L_{T}=2 L_{1}+2 L_{2}+4 L_{3}=0.637 \lambda_{\text {sub }} \approx 2 \lambda_{\text {sub }} / 3=5.378 \mathrm{~cm}$. Figure 11 shows the constructed structure including the reflector plate located at $H=\lambda_{\mathrm{o}} / 4$.

2.4. Measurement of Impedance Matching Parameters. To measure reflection coefficient $\left(\mathrm{S}_{11}\right)$ and VSWR, a 2-port vector network analyzer ZNB-20 from Rohde \& Schwarz ${ }^{\circledR}$ was used. Both parameters were measured from 1.5 to $3.5 \mathrm{GHz}$ [16] using 


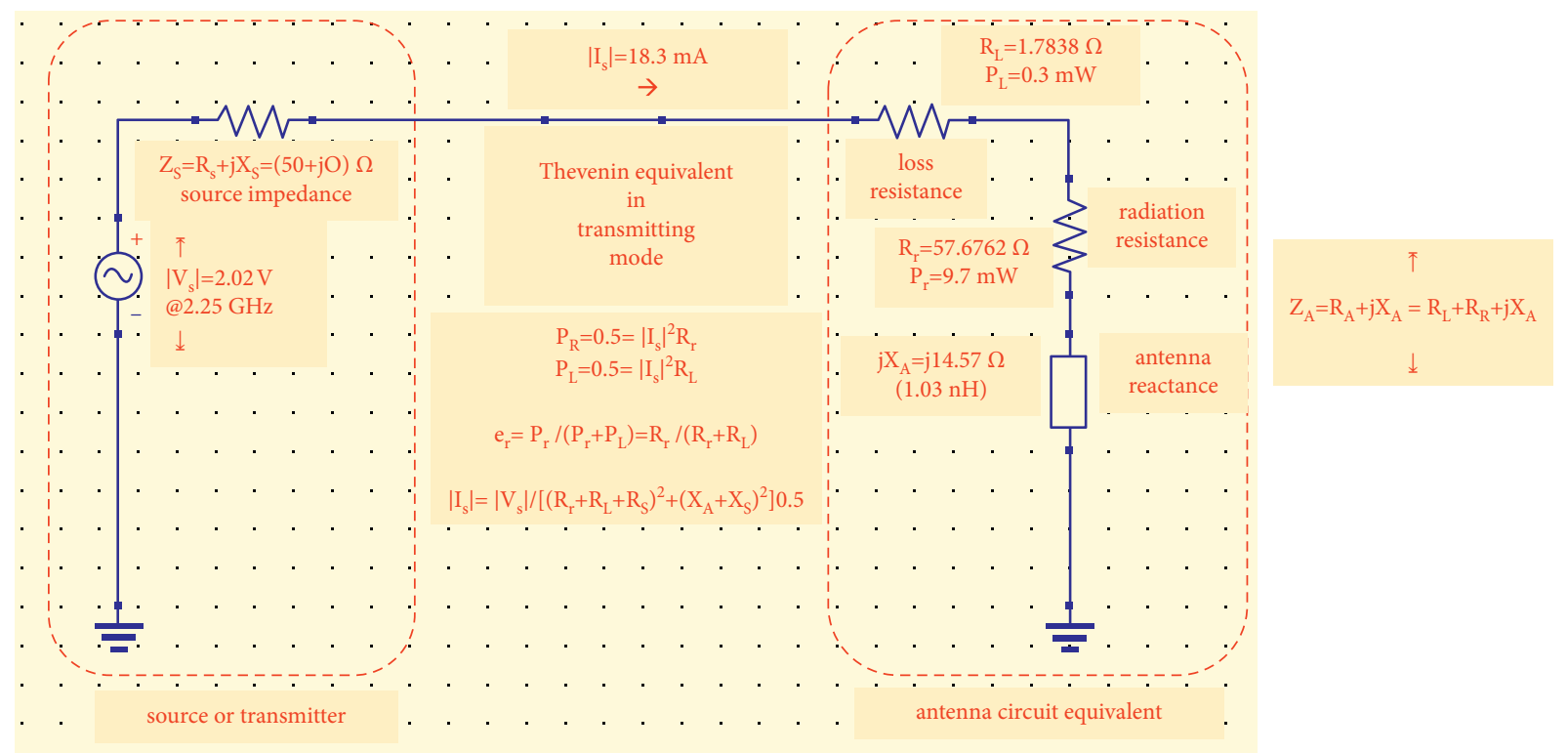

Figure 9: Antenna circuit analysis at $2.25 \mathrm{GHz}$.

TABle 5: Resonance and design frequencies analysis.

\begin{tabular}{lcc}
\hline Frequency $(\mathrm{GHz})$ & Impedance $(\Omega)$ & $\mathrm{S}_{11}(\mathrm{~dB})$ \\
\hline$f_{r 1}=1.05$ & $2.50+j 0$ & -0.79 \\
$f_{r 2}=1.50$ & $233.97+j 0$ & -3.30 \\
$f_{r 3}=1.91$ & $41.90+j 0$ & -20.07 \\
$f_{r 4}=4.07$ & $143.42+j 0$ & -6.38 \\
$f_{r 5}=6.53$ & $56.94+j 0$ & -22.80 \\
$f_{r 6}=7.25$ & $115.74+j 0$ & -8.03 \\
$f_{D}=2.25$ & $59.46+j 14.57$ & -15.96 \\
\hline
\end{tabular}

a strict measurement protocol including proper grounding, connector cleaning, equipment calibration with a Rohde \& Schwarz [17] ZV-Z235 kit, and a $50 \Omega$ high-performance cable from Maury Microwave Stability Plus series ${ }^{\circledR}$ [18].

2.5. Radiation Pattern Measurement. The radiation pattern measurements were carried out inside an anechoic chamber using a cylindrical coordinates measurement system. The antenna under test (UCPCA) was mounted on a $360^{\circ}$ rotation table, whose radiation field was received by a calibrated waveguide antenna (probe antenna) mounted on a vertical scanning device. Received data were processed using the system software. Axial ratio measurements were made according to relative positions between UCPCA and probe antenna, that is, horizontal diagram (HD) for vertical and horizontal polarization (VP and HP), as well as vertical diagram (VD) for vertical and horizontal polarization (VP and $\mathrm{HP}$ ). The position of the UCPCA main dipole defines the HD, while the probe antenna position defines HP and VP, respectively.

\section{Measurement Results}

For $S_{11}$ and VSWR measurements, VNA frequencies were from 1.5 to $3.5 \mathrm{GHz}$. Results for $\mathrm{S}_{11}$ are shown in Figure 12, where the lower frequency limit for measured bandwidth is
$1.671 \mathrm{GHz}$, while the higher limit is beyond the $3.5 \mathrm{GHz}$ upper-frequency limit considered in VNA, giving a measured bandwidth higher than $1835 \mathrm{MHz}$, which can be considered as a wideband response for the UCPCA. For frequency of interest of $f_{D}=2.25 \mathrm{GHz}, S_{11}$ is $-24.68 \mathrm{~dB}$ meaning a reflection of $0.34 \%$ for a $50 \Omega$ matching impedance $(V S W R=1.124)$. Figure 12 also shows the antenna reflection coefficient for simulation, which behaves like the measurements. It can be seen that simulation curve follows measurement curve changes with some differences, which are due to the precision considered for the simulation.

In order to show results regarding radiation, Figure 13 shows simulated magnitudes of electric field radiation patterns corresponding to (a) ColPol plot as a function of "theta" for different angles "phi" (XZ plane), (b) CrossPol plot as a function of "theta" for different angles "phi" (XZ plane), (c) ColPol plot as a function of "phi" for different angles "theta" (XY plane), and (d) CrossPol plot as a function of "phi" for different angles "theta" (XY plane). Figure 14 shows simulated axial ratios in $\mathrm{dB}$ as a function of "theta" for $\mathrm{phi}=0$ and phi $=90$ degrees. Markers in Figure 14 show the $-3 \mathrm{~dB}$ threshold to consider circular polarization in practical terms.

Figure 15 shows normalized electric field radiation patterns in polar coordinates, where the maximum measured gain was $6 \mathrm{dBi}$. The 0 -degree direction represents the $z$-axis, while the 90 -degree direction represents the $x y$-plane. 
TABLE 6: Surface electric current distributions at different instants of time for resonance frequencies $f_{R 3}=1.91 \mathrm{GHz}$ and $f_{R 5}=6.53 \mathrm{GHz}$, as well as for the design frequency $f_{D}=2.25 \mathrm{GHz}$.

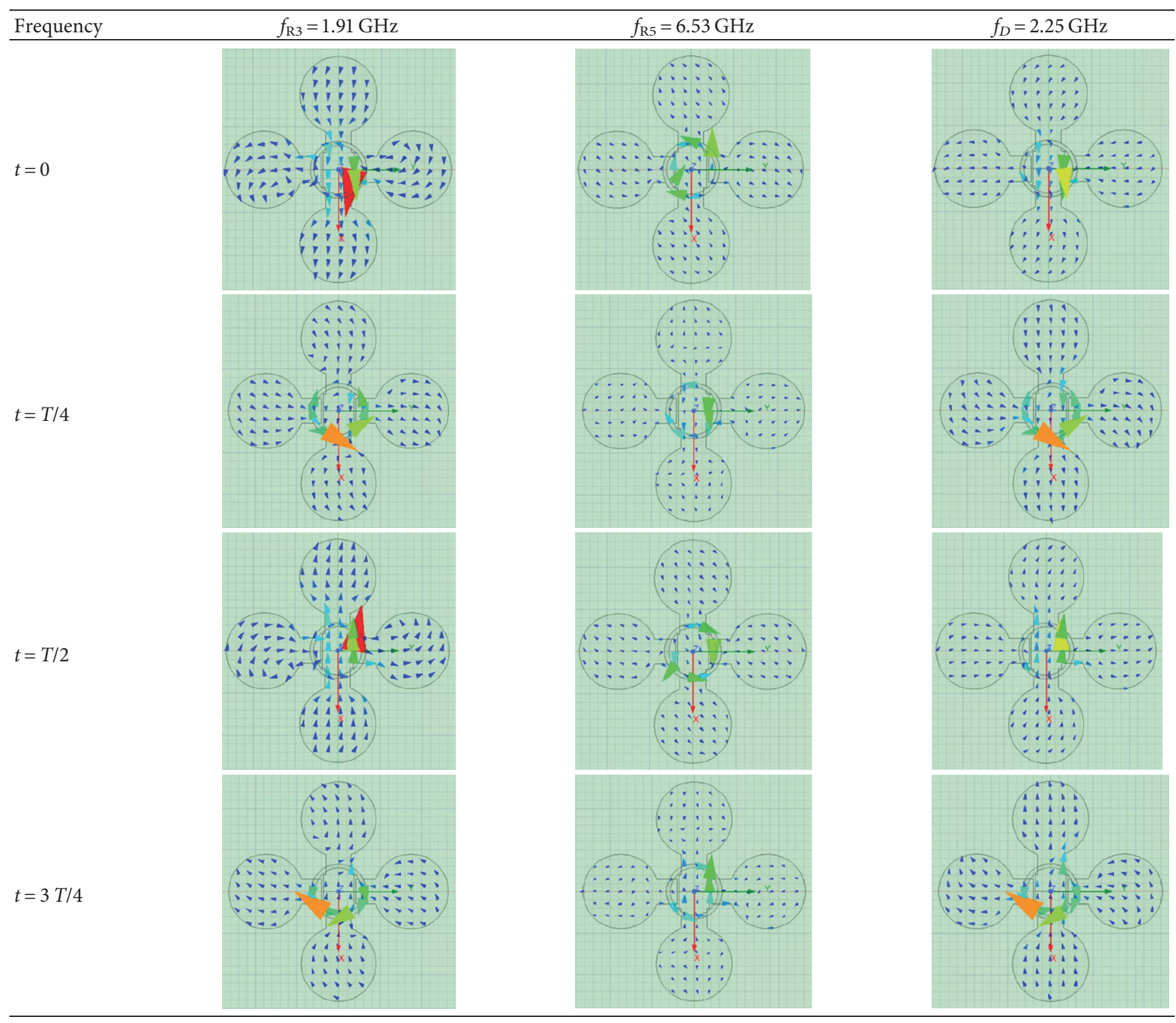

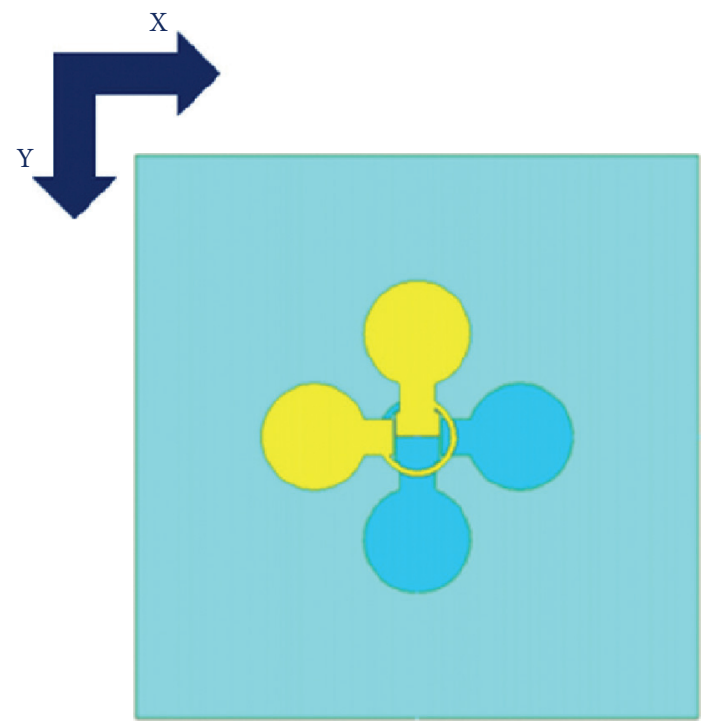

(a)

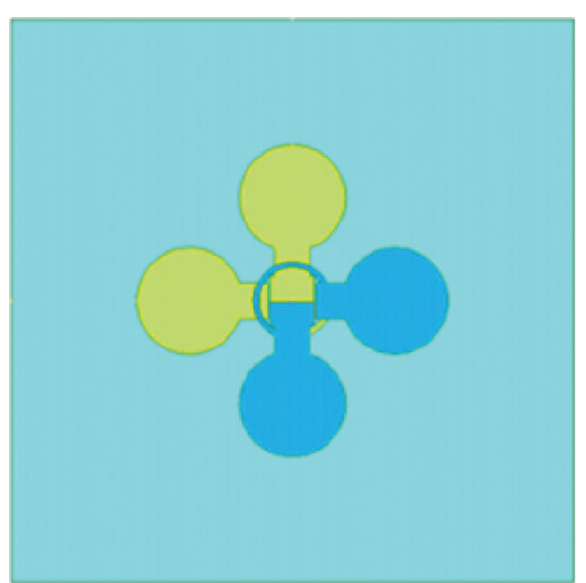

(b)

FIGURE 10: Both faces of UCPCA geometry: (a) top and (b) bottom. 


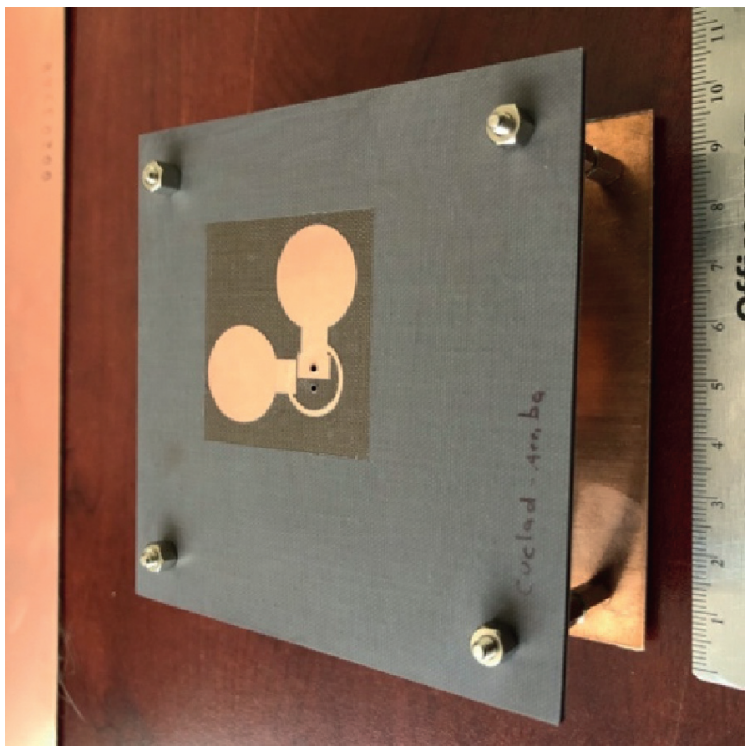

FIgURE 11: UCPA antenna.

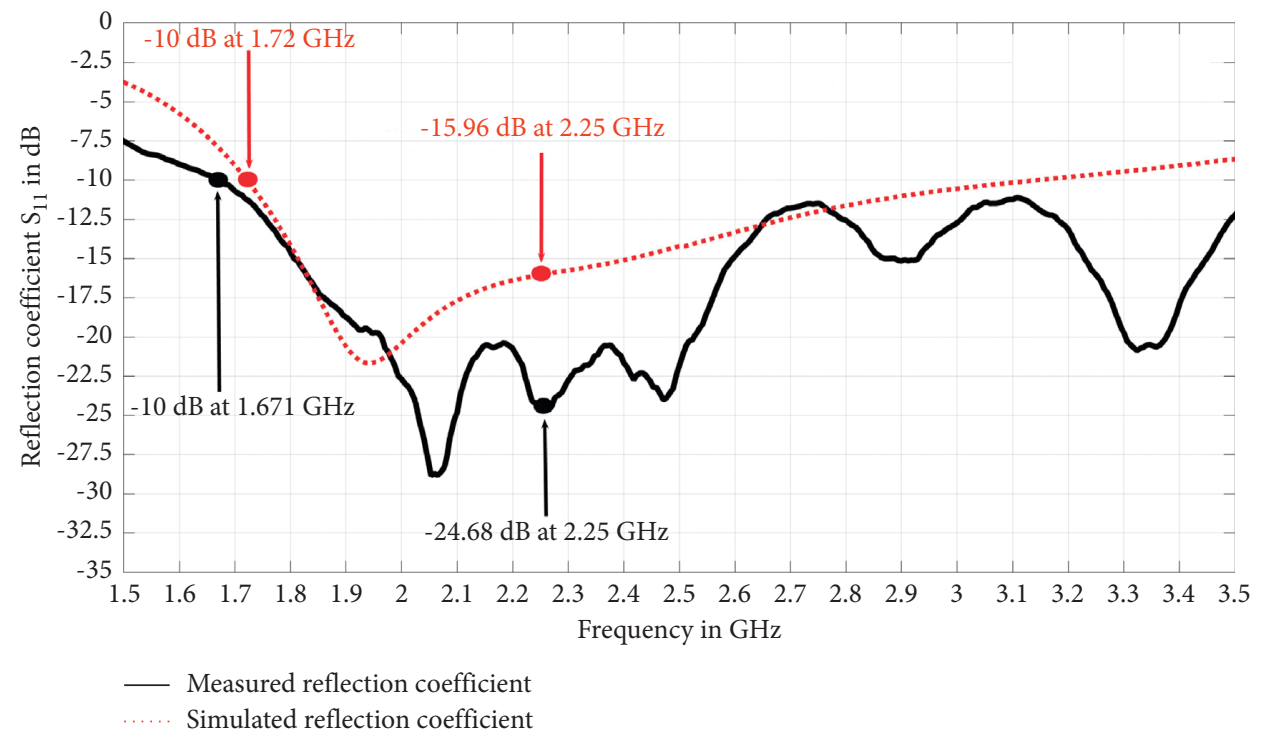

Figure 12: Simulated and measured reflection coefficient for the optimized antenna from 1.5 to 3.5 .

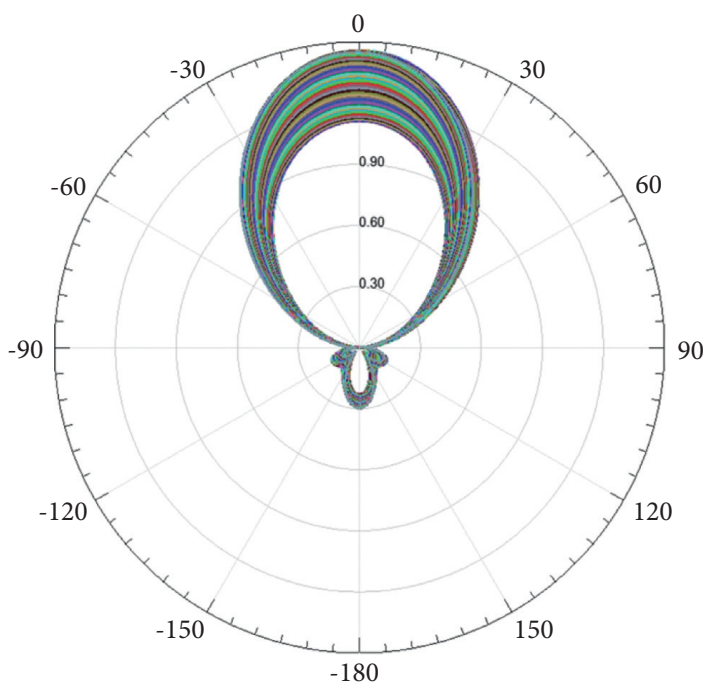

(a)

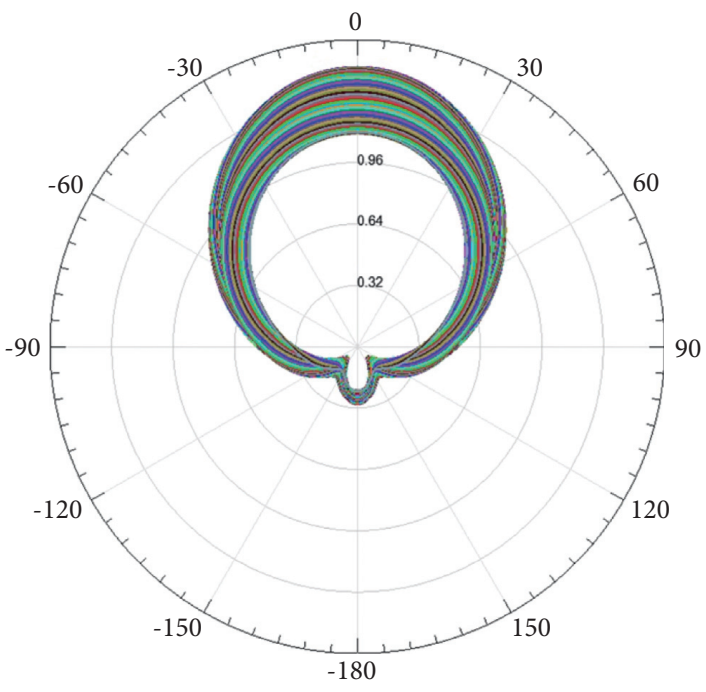

(b)

Figure 13: Continued. 


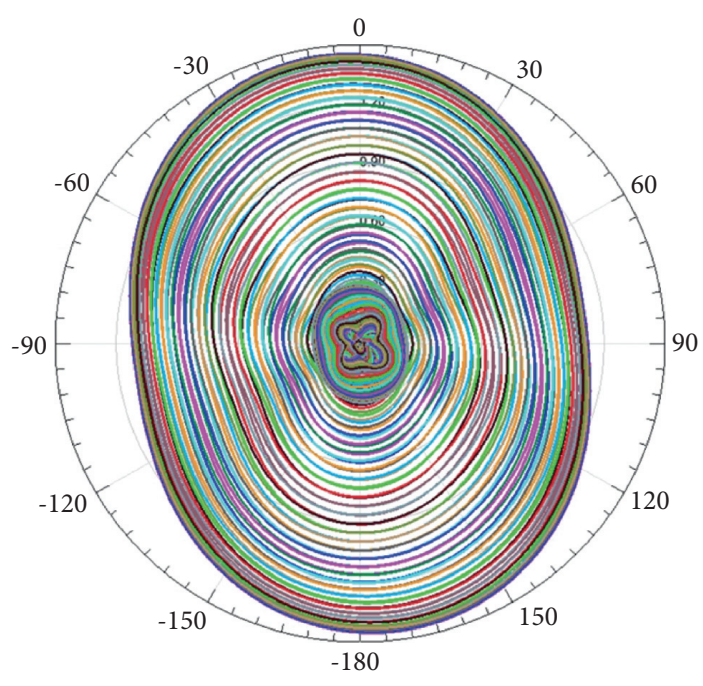

(c)

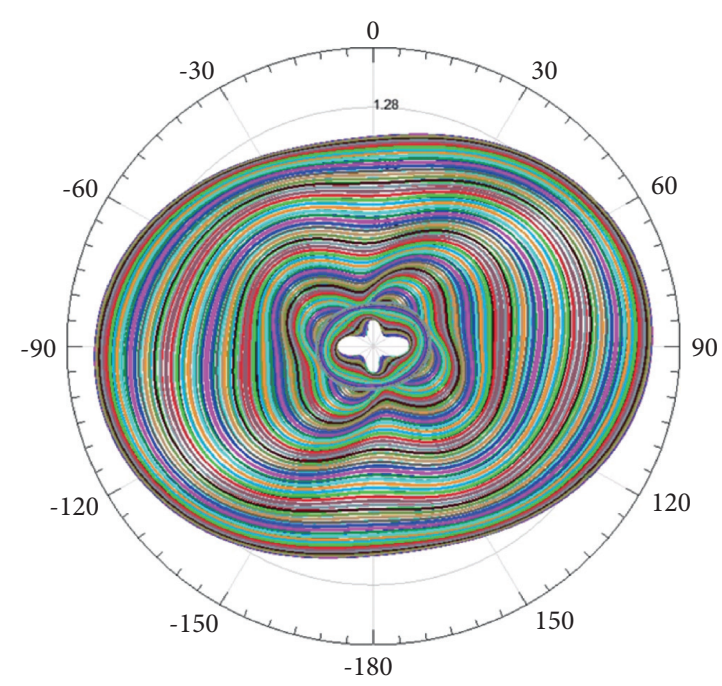

(d)

Figure 13: Simulated magnitude of electric field radiation patterns for the optimized antenna.

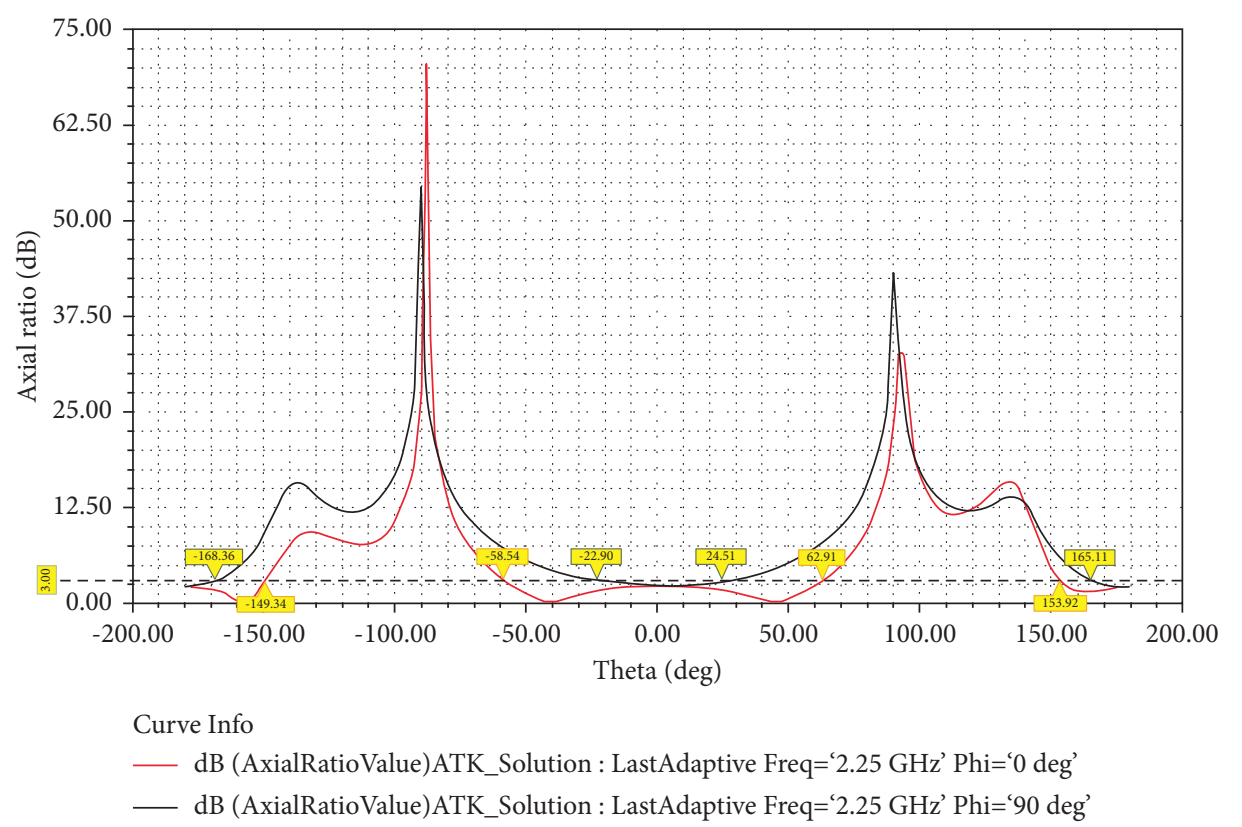

FIGURE 14: Simulated axial ratio of the optimized antenna as function of angular coordinates.

Figures 15(a) and 15(b) were obtained measuring the HD considering HP and VP of the probe antenna, respectively, while Figures 15(c) and 15(d) show measurements of the VD considering also HP and VP of the probe antenna, respectively. HD was obtained placing the main dipole horizontally, while VD was obtained placing the main dipole vertically. The main dipole is formed by the two horizontal monopoles appering in Figures 3(a) and 3(b).

The measured axial ratios were obtained comparing the magnitude of orthogonal field patterns for each degree for both $\mathrm{HD}$ and VD. The upper limit for axial ratio in practical terms to consider circular polarization is $3 \mathrm{~dB}$ which is indicated by the dotted horizontal red lines in Figure 16.
Measured axial ratios were obtained from $0^{\circ}$ to $360^{\circ}$ as shown in Figure 16(a) for HD and Figure 16(b) for VD.

As it can be seen, when comparing simulations with measurements there are some differences, so it is important to mention that in measurements the back copper flat plate (reflector) was made of a double-face Cuclad-250 laminate without removing any copper, while in simulations, it was modeled by a plane (null thickness) that acted as a perfect electrical conductor boundary condition. In measurements, the real design includes 4 metal poles to keep the antenna PCB apart with the reflector, while in measurements, those poles were not included. For the real design, the antenna feed is an SMA connector with a coaxial cable, while in measurements, a lumped port was considered. 
Horizontal Diagram-Vertical Polarization

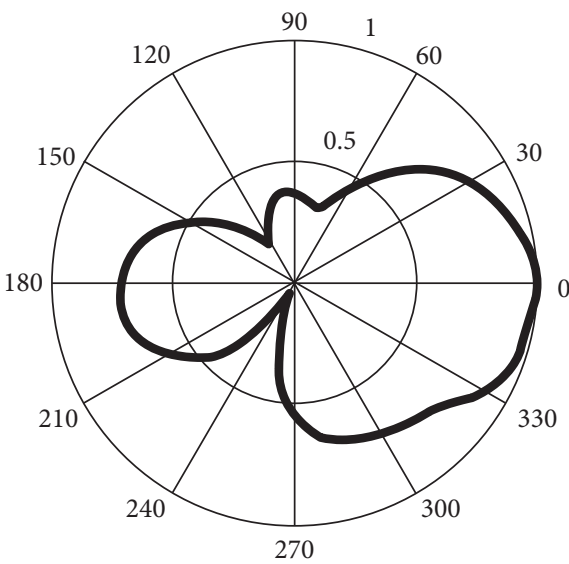

(a)

Vertical Diagram-Vertical Polarization

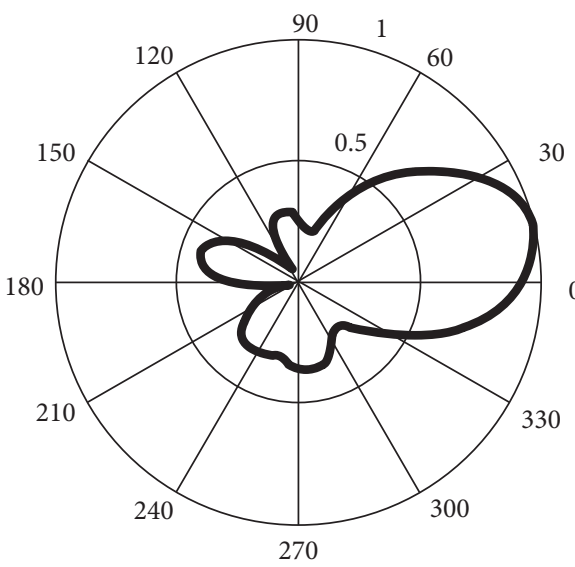

(c)
Horizontal Diagram-Horizontal Polarization

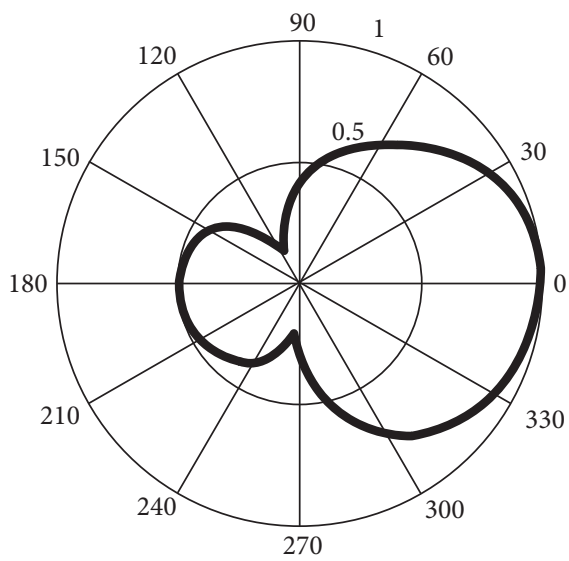

(b)

Vertical Diagram-Horizontal Polarization

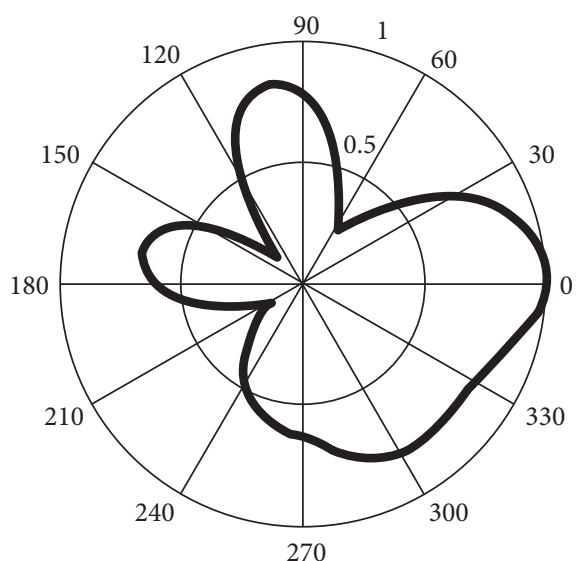

(d)

FIGURE 15: Radiation pattern measurements of the optimized antenna at $2.25 \mathrm{GHz}$ : (a) horizontal diagram-vertical polarization, (b) horizontal diagram-horizontal polarization, (c) vertical diagram-vertical polarization, and (d) vertical diagram-horizontal polarization.

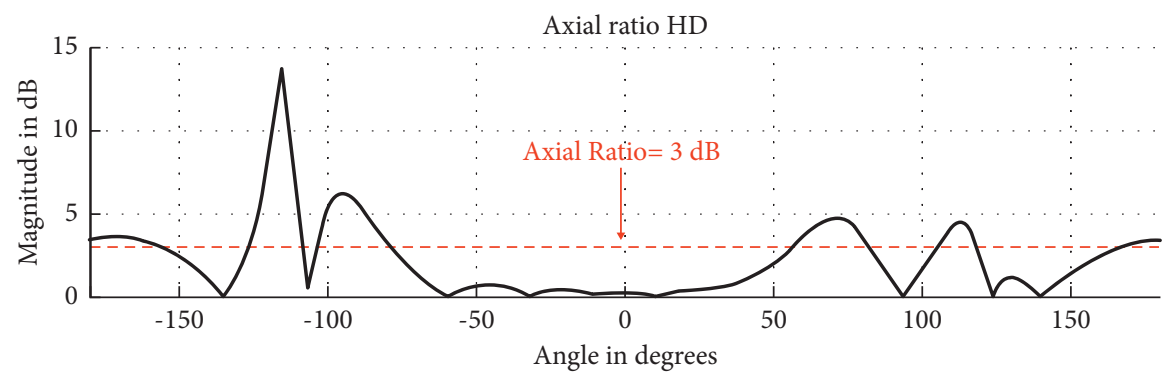

(a)

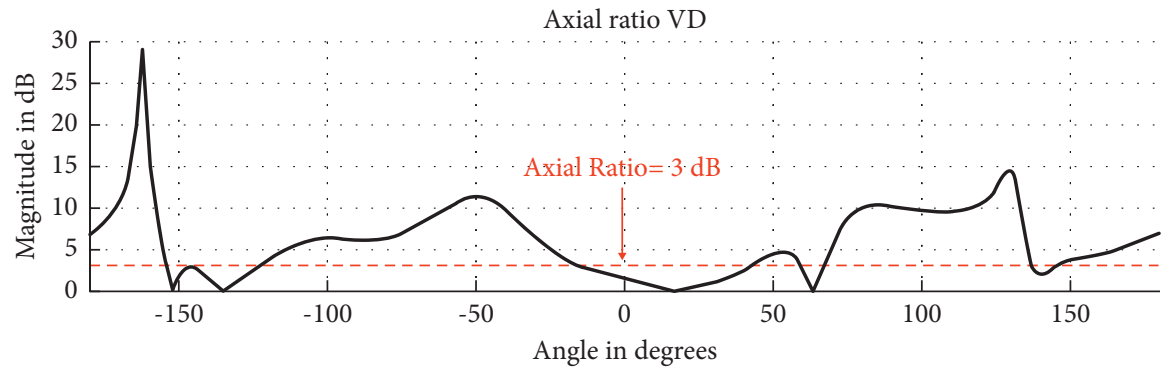

(b)

FIGURE 16: Measured axial ratio as function of angular coordinates for (a) horizontal diagram (HD) and (b) vertical diagram (VD). 


\section{Conclusions}

In this article, an optimized design of a UCPCA using the optimization tools based on genetic algorithms included in the 3D electromagnetic simulation software Ansys HFSS for applications on CubeSat small satellites is presented. The genetic algorithm method was focused on VSWR and axial ratio, and it was used for optimizing the antenna geometry before fabrication and measurements. The proposed antenna showed acceptable values for reflection coefficient $\left(S_{11}\right)$, VSWR, and axial ratio. From those results, it was concluded that applying genetic algorithms for optimizing antenna performance is a proper technique in antenna design for CubeSat small satellites. The resulting antenna works at S-band frequencies and showed a measured $-10 \mathrm{~dB}$ bandwidth higher than $1835 \mathrm{MHz}$ with a central operation frequency of $2.25 \mathrm{GHz}$, at which reflection coefficient $\left(S_{11}\right)$, VSWR, minimum axial ratio in the broadside direction, and the maximum gain were $-24.68 \mathrm{~dB}$, $1.124,0.22 \mathrm{~dB}$, and $6 \mathrm{dBi}$, respectively. Simulation results are very similar in behavior to those obtained by measurements. The antenna is a two-layer crossed-dipole microstrip antenna built on a $10 \times 10 \mathrm{~cm}$ Cuclad-250 substrate with a back finite square copper plate at $\lambda / 4$ of design frequency in free space and with the same dimensions as microstrip antenna. The backplate was included to improve the gain and the axial ratio with relatively little impact on the reflection coefficient observed by means of simulations. The antenna meets the requirements of the CubeSat standard and is ready for prespace testing. The central operation frequency and the bandwidth make the antenna suitable for transmission of telemetry and payload data from space to ground, showing acceptable impedance matching (reflection coefficient), circular polarization (axial ratio), and gain. This work offers an original ultrawideband antenna with circular polarization at S-band frequencies as an alternative to commercial products for CubeSats. Comparing to those standing designs shown in Table 1, the purposed antenna has similar and even higher $-10 \mathrm{~dB}$ bandwidth, while the gain is the average. The simulated $3 \mathrm{~dB}$ axial ratio bandwidth is higher than the ones shown in Table 1.

\section{Data Availability}

The data used to support the findings of the study are available from the corresponding author upon request.

\section{Conflicts of Interest}

The authors declare that they have no conflicts of interest.

\section{Acknowledgments}

The authors would like to thank Universidad Autonoma de Zacatecas, Universidad Autonoma de San Luis Potosi, and Instituto Politecnico Nacional in Mexico for the facilities granted for the use of their corresponding infrastructures for microwave/radio frequency measurements.

\section{References}

[1] Cal Poly San Luis Obispo and Stanford University, "CubeSat design specifications," San Luis Obispo and Stanford, CA, USA, 2021, http://emits.sso.esa.int/emitsdoc/ESA_HQ/AD3_cds_rev13_final.pdf.

[2] Cal Poly San Luis Obispo and Stanford University, "The CubeSat program," San Luis Obispo and Stanford, CA, USA, 2021, http://www.cubesat.org.

[3] S. Gunaseelan and M. Murugan, "High gain patch antenna for CubeSat," in Proceedings of the International Conference on Wireless Communications, Signal Processing and Networking, pp. 52-54, Chennai, India, March 2016.

[4] F. E. Tubbal, R. Raad, and K. Chin, "A wideband F-shaped patch antenna for S-band CubeSats communications," in Proceedings of the International Conference on Signal Processing and Communication Systems, pp. 1-4, Surfers Paradise, Australia, December 2016.

[5] C. Ángel Figueroa-Torres, J. Luis Medina-Monroy, H. LobatoMorales, R. Arturo Chávez-Pérez, and A. Calvillo-Téllez, "A microstrip antenna based on a standing-wave fractal geometry for CubeSat applications," Microwave and Optical Technology Letters, vol. 58, no. 9, pp. 2210-2214, 2016.

[6] O. F. Gonzalez-Palacios, R. E. Diaz-Vargas, J. A. HeraudPerez, and S. B. Correa-Erazo, "S-band koch snowflake fractal antenna for CubeSat," in Proceedings of the IEEE ANDESCON, pp. 1-4, Arequipa, Peru, October 2016.

[7] J. Sosa-Pedroza, S. Peña Ruiz, and F. Martínez-Zúñiga, "A $2.4 \mathrm{GHz}$ cross rhombic antenna for a cube satellite application," International Journal of Antennas and Propagation, vol. 2014, Article ID 268151, 10 pages, 2014.

[8] H. Lobato-Morales, S. Villarreal-Reyes, E. Guerrero-Arbona et al., "A $2.45 \mathrm{GHz}$ circular polarization closed-loop travelingwave antenna for cubesats," in Proceedings of the International Conference on Electronics, Communications and Computers (CONIELECOMP), Cholula, Mexico, February 2019.

[9] A. Ygnacio-Espinoza, D. Peñaloza-Aponte, J. AlvarezMontoya, A. Mesco-Quispe, and M. Clemente-Arenas, "Quasi-transparent meshed and circularly polarized patch antenna with metamaterials integrated to a solar cell for S-band CubeSat applications," in Proceedings of the 2018 International Conference on Electromagnetics in Advanced Applications (ICEAA), pp. 605-608, Cartagena, Colombia, September 2018.

[10] J. M. Johnson and V. Rahmat-Samii, "Genetic algorithms in engineering electromagnetics," IEEE Antennas and Propagation Magazine, vol. 39, no. 4, pp. 7-21, 1997.

[11] Y. Rahmat-Samii, J. M. Kovitz, and H. Rajagopalan, "Natureinspired optimization techniques in communication antenna designs," Proceedings of the IEEE, vol. 100, no. 7, pp. 2132-2144, 2012.

[12] E. Garduño-Nolasco, J. Sosa-Pedroza, and H. Jardón-Aguilar, "A printed volcano smoke antenna for personal communication systems," Microwave and Optical Technology Letters, vol. 58, no. 11, pp. 2592-2595, 2016.

[13] H. H. Tran, I. Park, and T. K. Nguyen, "Circularly polarized bandwidth-enhanced crossed dipole antenna with a simple 
single parasitic element," IEEE Antennas and Wireless Propagation Letters, vol. 16, pp. 1776-1779, 2017.

[14] LPKF Laser and Electronics, LPKF ProMat S104, LPKF Laser and Electronics, Garbsen, Germany, 2021.

[15] Altium Designer, Fácil, Potente y Moderno El Sistema de Diseño de PCB Más Reconocido del Mundo, Altium Designer, San Diego, CA, USA, 2021

[16] Rohde \& Schwarz, R\&S ${ }^{\circledR}$ ZNB-20 Vector Network Analyzer, Rohde \& Schwarz, Munich, Germany, 2021.

[17] TestEquity, ZV-Z235 Calibration Kit, TestEquity, Moorpark, CA, USA, 2021.

[18] Maury Microwave, Stability Plus Microwave/RF Cable Assemblies, Maury Microwave, Ontario, CA, USA, 2021. 